University of Rhode Island

DigitalCommons@URI

Open Access Master's Theses

1957

\title{
Mellitonitrile and Polyphthalocyanines
}

Joseph A. Antonelli

University of Rhode Island

Follow this and additional works at: https://digitalcommons.uri.edu/theses

\section{Recommended Citation}

Antonelli, Joseph A., "Mellitonitrile and Polyphthalocyanines" (1957). Open Access Master's Theses.

Paper 1361.

https://digitalcommons.uri.edu/theses/1361

This Thesis is brought to you for free and open access by DigitalCommons@URI. It has been accepted for inclusion in Open Access Master's Theses by an authorized administrator of DigitalCommons@URI. For more information, please contact digitalcommons-group@uri.edu. 


\section{MELLITONITRILE AND POLYPHTHALOCYANINES}

BY

JOSEPH A. ANTONELII

A THESIS SUBMITFED IN PARTIAL FULFILLMENT OF THE REQUIREMENTS FOR THE DEGREE OF

MASTER OF SCIENCE

IN

GHEMISTRY

UNIVERSITY OF RHODE ISLAND

1957 
MASTER OF SCIENCE THESIS

OF

JOSEPH A. ANTONELLI

Approved:

Major Professor

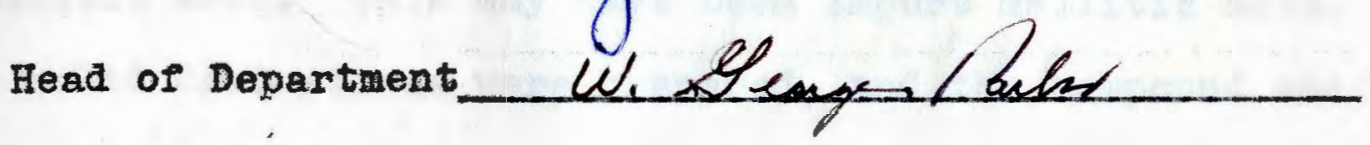

Dean of the College of

Arts and Selences ( 1

Director of Graduate Studies

UNIVERSITY OF RHODE ISLAND

1957 


\section{ABSTRACT}

Several methods were inveetigated in an attempt to gynthesize mellitonitrile which wa to be used to prepare a cross-IInked polymer with copper. The trimerization of butyne dinitrile with a one-to-one mixture of glacial acetic acid and pyriaine gave white crystalline product containing nitrogen. It was not characterized but may have been mellitonitrile. This product was lsolated by chromatography.

Oxidation of some of the eluates obtalned from the chromatographic separation of the trimerization mixtures gave a compound with a melting point close to that of mellitic acid. This may have been impure mellitic acid. No solid derivatives were prepared, and the compound was not characterized.

A modification in the Diels' preparation of hexamethylmelitate by the trimerization of dimethyl acetylenedicarboxylate gave an increased yield. A diluted catalyst was used.

A compound exhiblting phthalocyanine-like properties was prepared by the reaction of pyromellitic dianhydride with urea, borlo acid and eupric chloride. 
TABLE OF GONTENTS .................. $\frac{\text { Page }}{1}$

I. INTRODUCTION ................ 3

II. INVESTIGATION ................ . 7

A. DISCUSSION OF THE ATTEMPTED PREPARATION

OF MELLITONITRILE . . . . . . . . . . . 7

B. DISCUSSION OF THE PREPARATION OF

BUTYNE DINITRILE . . . . . . . . . . . 10

c. DISCUSSION OF REACTIONS TO PREPARE

POLYP HTHALOCYANINES . . . . . . . . . . . 11

D. DISCUSSION OF THE PREPARATION

OF MELLITIC ACID . . . . . . . . . . . 13

E. EXPERIMENTAL PROCEDURE .......... 14

Trimerization Reactions......... 14

Preparation of dimethyl acetylene-

dlearboxylate ............ 14

Trimerization of aimethyl acetylene-

dicarboxylate ........... 14

Preparation of acetylenedicarboxamide. . 16

Attempted trimerization of

acetylenedlcarboxamide . . . . . . 16

Preparation of butyne dinitrile . . . . 16

Attempted trimerization of butyne

dinitrile with acetic acld-pyridine

catalyst ............. 17

Attempted trimerization of butyne

dinitrile under high temperature

and pressure............ 19

Attempted trimerization of butyne

dinitrile under high temperature ... . 19

Attempted trimerization of butyne

dinitrile with cuprous ayanide..... 20

Attempted trimerization of butyne

dinitrile in ether.......... 20 
Oxidation of trimerization products.... $\frac{\text { Page }}{20}$ Resctions of pyromellitic acid and its derivatives............. 22

Reaction of pyromelitic acld with

lead thlocyanate.......... 22

Reaction of zine pyromellitate with

lead thlocyanate........... 22

Preparation of the tetraamide of pyromellitic actd . . . . . . . 22

Reaction of pyromellitotetraamide with phosphorus pentoxide ....... 22

Preparation of a phthalocyanine with pyromellitio dianhydride . . . . 23

Reactions involving mellitlc acld.... . 25

Preparation of mellitic acld from tetrachlorophthalic anhydride ..... 25 Attempted trimerization of butynediol . 25

Attempted preparation of a phthalocyanine with mellitic acld.......... 25

III. DISGUSSION OF RESULTS AND CONCLUSIONS . . . . 26

IV. SUMMARY . . . . . . . . . . . . 28

V. ACKNOWLEDGMENTS . . . . . . . . . . . 29

vI. BIBLIOGRAPHY . . . . . . . . . . 30

Pigures

1. Structure of Copper Phthalocyanine. . . . 5

2. Portion of a Polyphthalocyanine as proposed by Nelson 


\section{INTRODUCTION}

The preparation of hexacyanobenzene, or mellitonitrile, and its subsequent polymerization to a phthalocyanine type polymer was the primary object of thle research. The metal phthalocyanines represent some of the most stable organie compound. and possess interesting properties. They are planar, h1ghly conjugated moleeules, which can be recrystallized from concentrated sulfurle acid. They sublime at very high temperatures. The phthalocyanines are used malniy as plgments the most common of these being phthalooyanine blue (9).

Copper phthalocyanine, e typleal phthalocyanine, is prepered by the reaction of four molecules of phthalonttrile and one atom of copper.

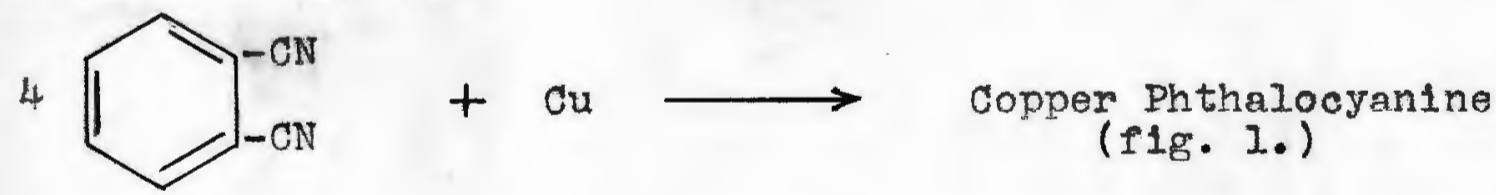

An exhaustive study of the structure and dimensions of the phthalocyanines by $\mathrm{x}$-ray diffraction has shown that thelr central portlons are porphyrin-like structures (16). (F1gure 2.)

It 1s possible that mellitonitrile can be polymerized to a simllar substance, and the resulting polymer, copper polyphthalocyanine, would be linear and highly oross-linked. Nelson made a stereochemical study of the so-called polyphthalocyanines, and he concluded that all bond angles and bond strains in such a compound were stereochemically possible. He further stated, however, that phthalonitrile would have to be used as a cross-linking agent if crose-linking were to 
take place between every second unit of the polymer.

(F1gure 2.) This long chain, cross-linked polymer would be sheet-like in form and quite stable. Its high degree of conjugation might posalbly make the polymer electrical conducting (15). 


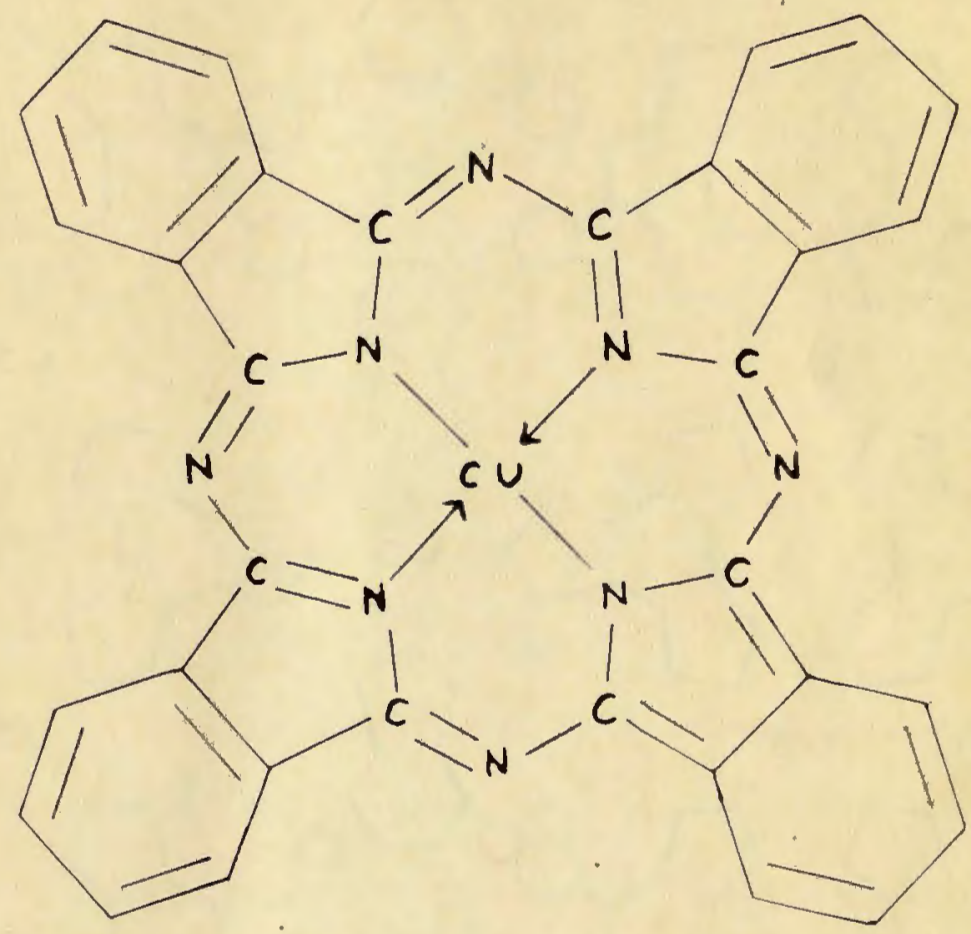

Figure 1. Structure of Copper Phthalocyanine. 


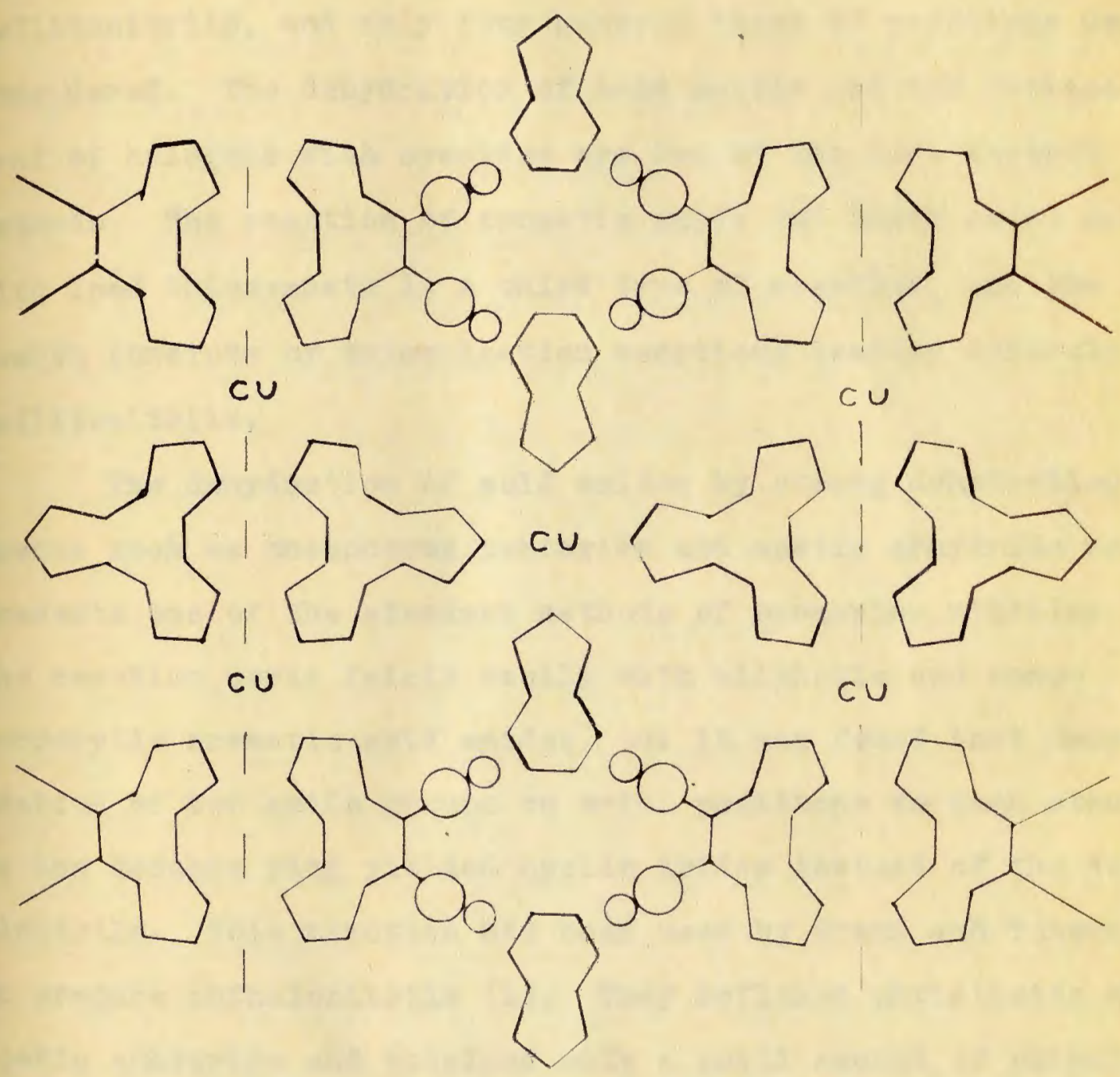

F1gure 2. Portion of a Polyphthalocyanine as proposed by Neloon. 


\section{INVESTIGATION}

A. DISCUSSION OF THE ATTEMPTED PREPARATION OF MELLITONITRILE

The attempted preparation of mellitonitrile represented the major portion of this research. Many methods of preparing nitriles are not feasible for the preparation of melittonitrile, and only four general tjpes of reactions were considered. The dehydration of acid amides and the replacoment of halogene with cyanides are two of the more general methods. The reaction of aromatio acids and their metal salts with lead thlocyanate is a third type of reaction, and the fourth conglste of trimerization reactions leading directiy to mellitonitrile.

The dehydration of acid amides by strong dehydrating agents such as phosphorus pentoxide and acetic anhydride represents one of the standard methods of preparing nitriles. The reaction works falriy easily with aliphatic and monocarboxylic aromatic aold amides, but it was found that dehydration of two amide groups on ortho positions to each other on the benzene ring ylelded cyclic Imldes ingtead of the desired dinitrile. This reaction had been used by Braun and Tcherniac to prepare phthalonitrile (1). They refluxed phthalamide with acetic anhydride and obteined only a smell amount of phthalonitrile. The reaction was attempted with pyromellitotetraamide but was not successful.<smiles>COc1cc(ON)c(ON)cc1ON</smiles>

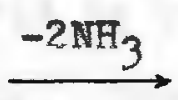<smiles>O=c1[nH]c(=O)c2cc3c(=O)[nH]c(=O)c3cc12</smiles> 
only the dilmide was formed. Dehydration of mellitohexaanlde was not attempted because it was expeoted to react in the same manner.

The replacement of a halide with cyanide is another general method of preparing nitriles. The reaction is simple, fast, and produces good ylelds with alkyl compounds. Aromatic halides do not work well, however. Nelson attempted to prepare melitonitrile by a replacement reaction using hexalodobenzene and hexabromobenzene with potassium cyenide (15). The reactions were unguccessful.

Nelson also attempted the Rosenmund-von Braun nitrile synthesls with hexalodobenzene and hexabromobenzene (15). The resction consieted in the heating of the aromatio halide with cuprous cyanide in pyridine solution. Th1s was also unsuccessful.

The reaction of aromatic acids and their zinc salte with lead thiocyanate or phospham wes suggested by Migridichian as a method of preparing aromatic nitriles (13). Much work was done by Nelson using thig method, but his attempts were unsuccessful (15). The resction consisted in heating a mixture of the acid or lts zino galt with lead thiocyanate and sea sand in a high racuum sublimation apperatus. Nelson did obtain some products containing nitrogen, but they were not characterized. The percentages of nitrogen in the compounds were not that of mellitonitrile.

The direct trimerization of butyne dinitrile or dieyanoacetylene appeared to be $a$, very promising method of preparing melittonitrile. Diels trimerized dimethyl acetylene- 
aicarboxylate to hexamethylmellitate (5). A one-to-one mixture of glacial acetic acid and pyridine was added as catalyst to an equal volume of dimethyl acetylenedicarboxylate. The reaction was maintained at $-10^{\circ} \mathrm{C}$. and then allowed to stand at room temperature for a lons time. Crystals formed and were picked out. They were characterized by hydrolysis to mellitic acid. This procedure was duplicated and it was found that the reaction was more easily controlled and gave better yields by diluting the catalyst in benzene and by aropwise adition of the reactant wth stirring. The trimerization of butyne dinitrile was attempted using the same procedures with varying concentration of catalyst in benzene. The reaction was also attempted at different temperatures and pressures and with different catalysts. Chromatography was used as a means of separation in an attempt to obtain a sample of melitonitrile.

The dehydration of glyoxal cyanohydrin followed by trimerization was another possible route to mellitonitrile. However, Nelson reported dificulties in preparing the eyanohydrin and the reaction was not attempted (15).

It $1 \mathrm{~s}$ possible that oxaloacetic acid dinitrile would trimerize and with dehydration produce mellitonitrile. Oxaloacetic acid dinitrile could be made from diethyl oxaloacetate by methods analogous to those used to prepare butyne dinitrile. Masterson prepared diethyl oxaloacetate in ninety per cent jields by the method of Wislicenus (10). $3 \mathrm{NC}-\mathrm{CH}_{2} \mathrm{G}-\mathrm{CN}+3 \mathrm{Base} \longrightarrow 3 \mathrm{NC}-\overline{\mathrm{CH}}-\mathrm{CN}+3 \mathrm{Base} \cdot \mathrm{H}$ $3 \mathrm{NC}-\overline{\mathrm{CH}} \mathrm{C}-\mathrm{CN} \longrightarrow \mathrm{NC} \underset{\mathrm{CN}}{\mathrm{CN}} \mathrm{CN}+3 \mathrm{CH}^{-}$ 
B. DISCUSSION OF THE PREPARATION OF BUTYNE DINITRILE

The preparation of butyne dinitrile was of prime importance in this investigation, and the method used was long and gave poor ylelds. Dimethyl acetylenedicarboxylate was prepared from the monopotasslum salt of acetylenedicarboxylic acid by esterification procedures (7). The ester was then allowed to react with aqueous ammonia to form the diamide of acetylenedicarboxyl1c ac1d. The dehydration of the diamide yielded butyne dinitrile. The process used for dehydration of the diamide was that of Moureu and Bongrand (14). Modifications in the procedures were used in an effort to increase jlelds of the intermediates but were successul only in the preparation of dimethyl acetylenedicarboxylate. There was a possibilitg that butyne dinitrile might have been prepared by the uee of a Grignard reagent. An acetylenic Grignard reagent added to a solution of cyanogen chloride in ether with subsequent hydrolysis would yield an acetylenic nitrile (13). Because acetyienedimagnesium bromide can be made, it is conceivable that it right react with two moles of cyanogen chloride to produce dicyanoacetylene. McNally attempted the reaction using cyanogen and was unsuccessful (II).

$\mathrm{BrMg}-\mathrm{C} \equiv \mathrm{C}-\mathrm{MgBr}+2 \mathrm{ClCN} \longrightarrow \mathrm{HC}-\mathrm{C} \equiv \mathrm{C}-\mathrm{CN}+\mathrm{MgBr}_{2}+\mathrm{MgCl}_{2} \cdot$ 
C. DISCUSSION OP REACTIONS TO PREPARE POLYPHTHALOCYANINES

Many methods of preparing phthalocyanines have been developed ranging from vapor phase procedures to simply heating the reactants in an open beaker. Although copper was the most commonly used metal and formed the most stable compound, beryllium, magnestum, calclum, barlum, zinc, cadmlum, nickel, manganese, cobalt, chromium, lead, tin, and Iron have all been used in the preparation of the phthalocyanines (4).

Fundamentally the reactione consisted in the interaction of the aromatic dinitrile and the metal or metalic salt. or tho-cyanobenzamides, ortho-sulfobenzonitriles, or tho-halogenobenzonitriles, ortho-dihalogenobenzenes, and phthalle anhydride plus ammonia have all been used as reactants with the metals to prepare the metal phthalocyanines (4).

Three general methods have been considered for the preparation of a polyphthalocyanine. The flrst was the reaction of mellitonitrile or pyromelitonitrile with metalic copper. The reaction of cupric chloride with mellitonitrile or pyromelittonitrile was the second method (4). Nelther of the two methods was used because of the lack of mellitonitrile and pyromellitonitrile. It was belleved, however, that the reactions would work easily because of the ease with which the hthalooyanines form. The polyphthalooyanines were belleved to be possible sterically.

The third method involved the heating of pyromeliltic danhydide or mellitic acid with boric acld, urea, and cupric chloride (4). This reaction was attempted with both pyro- 
mellitic danhydride and with mellitic acid. With pyromellitic dianhydide a bright, blue-green, lustrous compound was formed. It resembled a phthalocyanine in that it was highly coloured and recryetallized from concentrated sulfurlo ac1d. The compound was not characterized. The reaction with mellitic acld yielded a dark brow substance which did not resemble a phthalocyanine in color or in acid reprecipttation. This compound wa\& not characterized elther. 


\section{DISGUSSION OF THE PREPARATION OF MELLITIO ACID}

Melitic acld has been prepared by many methods but mostly in very small yields. The method of Felst (6) with modelcations by Nelson (15) has proven to be the most aucessful. Tetrachlorophthallc anhydride heated with potassium cyanide, cuprous cyanide, and potasstum hydroxide under pressure resulted in the replecement of the chlorides with cyantdes which were then hydrolyzed to carboxyl groups. Nelson's method of separation and purifleation included the precipitation of the ammonium salt of the acla from the reaction mixture and recrystalilation from concentrated nitrio acid.

Chaigneau developed a procedure for the preparation of mellitic acid in which he started with phenol (2). Phenol was converted to hexamethyl benzene, then to hexabromomethyl benzene, then to the hexaacetate and finally hydrolyzed to hexamethylol benzene. Oxidation of hexamethylol benzene ylelded mellitic ac1d. This procedure was used by Nelson but proved to be too time consuming and was discarded (15). Primerization of butynediol wes reported by Smlth as a means of preparing hexamethylol benzene which could be quantitatively oxidized to mellitic acid (17). Nelson reported unsuccessful results. Unsuccessful attempts were also made in this investigation.

Direct oxidation of hexamethyl benzene and charcoal were also reported as means of preparing mellitic ac1d, but the yields were very poor, and the procedure time coneuming. 


\section{E. EXPERIMENTAL PROCEDURE}

\section{Trimerization Reactions}

Preparation of dimethyl acetylenedicarboxylate: The monopotassium salt of acetylene dicarboxylic acld $(94.8 \mathrm{g.})$ was added to a mixture of $500 \mathrm{ml}$. absolute methanol and $98 \mathrm{ml}$. concentrated sulfurle acid in a three necked flask. The flask was fitted with a mechanical stirrer and two water condensers. Both condensers were furnlshed with calclum chloride arying tubes. The mixture was refluxed on a steam bath for three hours, cooled, and flltered. The precipitate was washed with ether, and the washings, along with an additional $150 \mathrm{ml}$. ether, were aded to the filtrate. A saturated salt solution $(325 \mathrm{ml}$.) was added, and the ether layer was removed. Five extractions with ether were made and combined. These were washed with water and then with saturated sodium carbonate. The ether solution was dried over anhydrou magnesium sulfate, and the ether solvent was distilled of on a steam bath. The residual liquid was vacuum alstilled, and the fraction boiling at $91^{\circ} \mathrm{C}$. to $97^{\circ} \mathrm{C}$. was selected as the product. The yield was $41.2 \mathrm{~g}$. (45 ger cent). This yield was increased to approxlmately 80 per cent in a subsequent reaction by using $800 \mathrm{ml}$. methanol and refluxing for 24 hours. The ether extractions were increased to 10 in the modifled procedure.

Primerization of dimethyl acetylenedicarboxylate: Hexamethyl melittate was prepared by the Diels trimerization of dinethyl acetylenedicarboxylate. A one-to-one mixture (by volume) of 
glaclal acetic acld and pyridine $(3 \mathrm{g.})$ was added to an equal volume of the ester. A violent reaction took place almost immediately and the solution turned dark. The reaction was kept below $10^{\circ} \mathrm{C}$. and then allowed to stand at room temperature for approximately one week. Some crystals were formed and removed with a spatula. They were recryatalItzed from acetic acid. Only about $25 \mathrm{mg}$. of product was obtained.

The reaction was repeated using a dilute solution of catalyst. One gram of the catalyst was diluted in $50 \mathrm{ml}$. benzene and cooled in an 1ce bath. Dimethyl acetylenedicarboxylate $(3 \mathrm{~g} \cdot)$ was added dropwlse under mechanlcal agltation. The reaction was much slower but still formed a dark tarry substance. The benzene wae allowed to evaporate and the tarry mass set. After stending for about two weeks cryatals formed and were removed. The jield was about $0.2 \mathrm{~g}$. In another reaction the ester $(3 \mathrm{~g} \cdot)$ was added aropwise to a solution of $0.5 \mathrm{~g}$. acetic acid-pyridine catalyst in $50 \mathrm{ml}$. benzene. This procedure ylelded approximately the same amount of ester as the preceding: $0.2 \mathrm{~g}$.

Two drops of the oatalyet diluted in $50 \mathrm{ml}$. benzene was then used with $3 \mathrm{~g}$. of the ester. A reaction took place, but after the reaction ceased, a portion of the mixture was tested wh one more arop of catalyst. It was found that the reaction was not complete so more catalyst was odded. The inal yield was $0.2 \mathrm{~g}$. Chromatography was then used to separate the trimerized product from the mixture, but the yields were not increased by any appreciable amount. 
Preparation of Acetylenedicarboxamide: Acetylenedioarboxamlde was prepared by the reaction of dimethyl acetylenedicarboxylate Wth aqueous amonia. The ester was added dropwise to $800 \mathrm{ml}$. of concentrated ammonlum hydroxide which was cooled in an 100 bath to $-10^{\circ} \mathrm{C}$. The addition was continued unt11 $20 \mathrm{ml}$. of the ester had been added. A mechanical stirrer was employed to keep the reaction agltated and was continued for one hour after all the ester had been added. The amide formed was filtered and bolled with ethanol and methanol. The reaction gave a yield of 12.3 grams.

Attempted trimerization of aoetylenedicarboxamide: Acetylenedicarboxamide $(5.6 \mathrm{~g} \cdot)$, phosphorus pentoxide ( $60 \mathrm{~g} \cdot)$, copper powder $(3.2 \mathrm{~g} \cdot)$, and cuprous chloride $(3.2 \mathrm{g.})$ were mixed in a glass pressure bottle. The bottle was elughed out with nitrogen, stoppered and heated in a loosely covered large steel bomb for protective purposee. A vigorous reaction took place when heated to approximately $100^{\circ} \mathrm{C}$. The mixture was extracted with acetone and methyl alcohol, but nothing could be recovered. An attempt wes made to sublime the residue, but no sublimate formed. A pölyphthalocyanine might possibly have been part of the residue, but it was not isolated or charaoterized.

Preparation of butyne dinitrile: The method of Moureu and Bongrand was used to prepare butyne dinitrile (14). Acetylenedearboxamide $(6 \mathrm{~g} \cdot), \mathrm{P}_{2} \mathrm{O}_{5}(50 \mathrm{~g} \cdot 1$, and gea send (100 g.) were mixed to a homogeneous state and then poured into four test tubes. The tubes were connected to a glass arm leading to a recelving tube in an acetone-dry ice bath at $-80^{\circ} \mathrm{C}$. The 
apparatus was then evacuated by means of a high vacuum pump, and $n$ trogen was introduced. The system was again evacuated to $5 \mathrm{~mm}$. pressure, and the tubes were heated to $220^{\circ} \mathrm{C}$. by quickly immersing in a hot 011 bath. The distillation was continued for 30 minutes, and a solid product formed in the recelving tube. When the recelver was allowed to come to room temperature, the crystals melted, and the liquid was collected. The yield was $1.28 \mathrm{~g} \cdot(31.14 \mathrm{per}$ cent $)$. The reaction was attempted using other apparatus, but no increase in yleld was obtained and cleaning difficulties were encountered.

Attempted trimerization of butyne dinitrile: The methods ued to trimerize dimethyl acetylenedicarbozylate were repeated using butyne dinitrile. One grem of butyne dinitrile was added dropwise to one gram of acetic acla-pyridine catalyot. A violent reaction took place and dark fumes evolved. A tarry subetance formed which set into a resinous mass after standing for approxlmately two hours. It appeared that high polymer formation had taken place. Chromatographic technique ylelded no cryetaline products.

The catalyst mixture was then diluted to $0.5 \mathrm{~g}$. In $50 \mathrm{~g}$. of benzene, and one gram of butyne dinitrile was added dropwise. The reaction was maintained at $0^{\circ} \mathrm{C}$. by an lce bath, and a mechanical stirrer was used for continuous agitation. The reaction was slowed considerably by the dilution of the catalyst, and the solvent took on a deep red color. The benzene solution was then passed through a chromatographic column which was prepared by methods described by W1lliams (18). Benzene was 
poured into a burette to the $25 \mathrm{ml}$. mark. A plug of flbre glese, saturated with benzene to remove a1r bubbles, was then inserted into the tube and pushed to the bottom. Fisher adsorbent alumina, 80-200 mesh, was then sprinkled Into the tube and allowed to settle. The adsorbent was added to 111 the tube to the $10 \mathrm{ml}$. mark. Another glase wool plug was inserted above the top of the adsorbent, and the column was allowed to draln. More benzene was added to prevent the solvent level from dropping below the level of the adsorbent. In this manner the alumina settled, and the column was ready for operation. The benzene solution from the reaction was poured into the top of the burette, and a definite separation was affected on the alumina. A bright yellow band appeared lowest on the column and was followed lmmediately by a red band. Benzene was used ae an eluent. Fractions of approximately $50 \mathrm{ml}$. were taken. The fractions obtained before the elution of the yellow and red bands left no residue upon evaporation at room temperature. Yellow and red residues were obtained upon evaporation of their respective eluates from the column. So little of each was obtalned, however, that they could not be analyzed. They both melted at approximately $185-200^{\circ} \mathrm{C}$. The large melting point range indicated that the Practions were probably 1mpure. No other sollds were isolated with the benzene eluent. Acetone and methyl alcohol were then used as elvents and only dark impure residues were obtained.

The same procedure was repeated with the glacial acetic acld and pyrialne cotalyst diluted $0.5 \mathrm{ml}$. In $100 \mathrm{ml}$. of benzene. The reaction behaved in the same manner and 
chromatography. was again attempted. The same bands were developed, but the fraction eluted before the yellow band ylelded some long clear crystals which sublimed at $220-225^{\circ}$. The compound was not made in a large enough quantity to provide for nitrogen analyals.

The attempted trimerization of butyne dinitrile with high temperature and pressure: The trimerization of butyne dinitrile was attempted under pressure. Dlcyanoacetylene (1.28 g.) was mixed with $0.5 \mathrm{~g}$. copper powder in a glass pressure bottle. The bottle was flushed with nitrogen and heated for 24 hours at $180^{\circ} \mathrm{C}$. The heat and pressure were sufficlent to convert the dinftrile to the gaseous state, and upon cooling the gas condensed. Cuprous chloride $(0.5 \mathrm{~g}$.$) was then added to the$ glass bomb, and the heating was continued for 8 hours. No condensation took place upon coollng and nothing was obtained. Extraction of the substance remaining in the bottle was attempted with acetone, methyl alcohol, and sulfurlo acid with negative reaults.

The attempted trimerization of butyne dinitrile with high temperature: Another attempt to trimerize butyne dinitrile was made at high temperature but at atmospheric pressure. In this attempt approximatel $1 \mathrm{~g}$. of butyne dinitrile was diluted in $25 \mathrm{ml}$. benzene and refluxed for 12 hours. At the end of the heating period a portion of the benzene colution was treated with one drop of the acetic acld-pyridine catalyat. A Vlgorous reaction took place indicating that the dicyanoacetylene had not reacted without catalyst. The remainder of the solution was treated with the catalyst and subjected to 
chromatography. The same products were isolated from this mixture as from the attempt at low temperature and pressure.

Attempted trimerization of butyne dinitrile with nickel cyanide: One gram of butyne dinitrile was then refluxed with benzene $(25 \mathrm{ml.})$ and nickel cyanide powder $(0.5 \mathrm{g.})$ as a catalyst. After refluxing for 8 hours, evaporation of the benzene yielded a minute amount of residue. It was similar to the residues obtained from the chromatographic separations. The catalyst used in this attempt was prepared by the method described by oopenhaver and Bigelow (3). A saturated solution of nickel chloride in ethyl alcohol was made, and HCN gas was passed through the solution. The gas was produced in a generator with $\mathrm{KCN}$ and $\mathrm{H}_{2} \mathrm{SO}_{4}$. Nickel oyanide was precipitated and collected. It was washed with water and heated to $175^{\circ} \mathrm{C}$. to convert it to the anhydrous salt.

Attempted trimerization of butyne dinitrile in ether: Butyne dinitrile was then treated with an ether solution of the acetic acia-pyridine catalyst at $0^{\circ} \mathrm{C}$. The same reaction took place as in the benzene solution, and chromatography yielded the same components.

Oxidation of the trimerization reactions' products: The red and yellow products isolated from the trimerization attempts were added to $15 \mathrm{ml}$. of 40 per cent $\mathrm{HNO}_{3}$ and refluxed for one hour. The solution turned dark and gave off dark fumes characteristic of $\mathrm{NO}_{2}$. The heating was atopped after the solution cleared. Evaporation to dryness yielded some 
crystals that melted at approximately $2800^{\circ} \mathrm{C}$. to $281^{\circ} \mathrm{C}$. An ingufficient amount was obtained to prepare a solid derivative. A mixed melting point determination with melitic acid did not markedly change the melting point, but the melting range was lengthened to $275^{\circ} \mathrm{C}$. to $284^{\circ} \mathrm{C}$.

Oxidation of all other eluates produced no solld. products. 
Reactions of pyromeli1tic acid and 1ts derlvatives

Reaction of pyromeliltic acid with lead thiocyanate: Ten grams of lead thiocyanate, alx grams of pyromellitic acid, and thirty grams of sea sand were mixed and heated in a high vacuun sublimation apparatus to $240^{\circ} \mathrm{C}$. and $5 \mathrm{~mm}$. pressure. A yellow sublimate formed containing sulfur but no nitrogen. The procedure vas repeated twice with the same results.

Reaction of zinc pyromellitate with lead thlocyanate: zinc pyromellitate was prepared by the method of Karmrodt (8). Five grams of the zinc salt of pyromellitic acid and ten grams of lead thiocyanate were mixed with an equal volume of sea sand. The mixture was heated to $300^{\circ} \mathrm{C}$. under $5 \mathrm{~mm}$. pressure in the sublimation apparatus. A sublimate formed containing no nitrogen.

Preparation of the tetraamide of pyromeliltic ac1d: Pyromeli1totetramide was prepared by the method described by Meyer and Steiner (12). Pyromellitle acld ( $10 \mathrm{~g} \cdot)$ was added to aqueous ammonia and a white precipitate of the ammonium salt was formed. Heating the ammonium salt overnight at $180^{\circ} \mathrm{C}$. converted it to the dimide of pyromellitic acid. The dilmide was then treated with aqueous amonia with vigorous stirring. An exothermic reaction ocourred and the mixture was cooled in an 1ce bath. The precipitated tetramide was collected, washed with alcohol and drled.

Reaction of oyromellitotetraamide with phosphorug pentoxide: Two grams of the tetraamide was mixed with four grams of 
phorphorus pentoxide and an equal volume of sand, and the mixture was heated to $250^{\circ} \mathrm{C}$. In a sublimation apparatus at $5 \mathrm{~mm}$. pressure. A white sublimate formed containing 12.0 per cent nitrogen by Kjeldahl analysis. Th1s agreed closely with the dimide of pyromellitic acld which contains 12.9 per cent nitrogen.

Preparation of a phthalocyanine with pyromeli1tic dianhydride: Twenty-six grame of urea and two grams of borlc acld were melted together in an open beaker by means of on 011 bath, and the temperature was raised to $150^{\circ} \mathrm{C}$. While the mixture was being stirred, a mixture of twenty grams of pyromeliltic dianhydride and four grams of anhydrous oupric chloride was dusted into the beaker. The reaction mixture became very thick and hardened, and the temperature was ralsed to $180^{\circ} \mathrm{G}$. After cooling the hardened mass was ground and washed with dilute $\mathrm{NaOH}$ and dilute HCL. The white residue was then dissolved in concentrated sulfuric acid. Dilution with water induced preclpitation. The white precipltate sublimed at $270^{\circ} \mathrm{C}$. and was belleved to be the dilmide of pyromellitic acid. A sodium fusion gave a positive test for nitrogen. The same procedure was repeated in a glass pressure bottle, and in this attempt a bright blue substance was formed. Orea (13 g.), borlo ecld ( $\mathrm{g} \cdot$ ), pyromellitlc dianhydride (10.g.), and cupric chlortae ( $2 \mathrm{~g} \cdot)$ were mixed in a glass bomb and heated overnight at $180^{\circ} \mathrm{C}$. The blue substance that formed was washed with dilute alkall and then with dilute acid. Concentrated sulfurlc acld was used to dissolve the substance and precipitation was effected by dilution with 1ce. A 
sintered glass filter was used to collect the precipitate. When heated with alkeli the substance gave off ammonla, and the solution turned blue. Sublimation was attempted in a vacuum apparatus. Dlrect flame from a Meeker burner was necessary to sublime the substance but some decomposition took place. 
Reactions involving mellitic acld

Preperation of mellitic acld from tetrachlorophthal1c anhydride: Mellitic acld was prepared by the method of Felst (6) using the modiflcations proposed by Helson (15).

Attempted preparation of mellitic acid by the trimerization of butynediol: One mole of butynediol, five grams of nickel acetate, and $250 \mathrm{ml}$. of alcohol were mlxed in a large steel bomb and heated for 30 hours at $120^{\circ} \mathrm{C}$. The alcohol was then evaporated off, the residue dissolved in water, and the nickel lons were removed with $\mathrm{H}_{2} \mathrm{~S}$. The solution was again evaporated to dryness and the residue subjected to oxidation with 40 per cent nitric ac1d. No mellitlc acld was obtained. The reaction was repeated in aqueous solution with negative results.

Attempted preparation of a phthalocyanine with mellitic acid: Mellitic acld ( $1 \mathrm{~g} \cdot)$, urea $(3.9 \mathrm{~g} \cdot)$, borlc acld $(0.15 \mathrm{~g} \cdot)$, and anhydrous cupric chlorlde $(0.6 \mathrm{~g}$.$) were mixed in a glase$ bomb and heated overnight at $180^{\circ} \mathrm{C}$. A daric brom substance was formed. It was washed with dilute $\mathrm{NaOH}$ and HCl. The reaction product was soluble in concentrated sulfuric acid but would not preclpitate upon dilution. Mhen heated with soda Iine the substance gave off amonia. 


\section{DISCUSSION OF RESULFS AND CONCLUSIONS}

The preparation of meliltonitrile by the trimerization of butyne dintrile showed definite signe of succese. Some solid crystals containing nitrogen were isolated from the reaction mixture. Although they were never charecterized because of their extremely small quantities, oxidation of the mixtures did yleld a product which melted at approximately $280^{\circ} \mathrm{C}$. to $281^{\circ} \mathrm{C}$. The hydrolysis of mellitonitrile 1tself would yield mellitic acid which melts at $286^{\circ} \mathrm{C}$. The product of the oxldations was belleved to be mellitic acld. Recrystalization was not attempted since such emall ylelds of the cryetals were obtained.

The dark tarry substances formed in the trimerization reactions indicated a large number of slde reactions. Probabiy polymerization of some type occurred.

As was evidenced by the various trimerization reactions of dimethyl acetylenedicarboxylate, the concentration of catalyet had a definite effect on the quantity of trimerized product produced. The resction using equal quantities of catalyst and reactant was too vigorous, and it appeared that most of the reactant went into high polymer reactions. By allution of the catalyat the reaction was slowed considerably and more trimerized product was obtained. High dilution of the catalyst produced an incomplete reaction. only one attempt was made to dehydrate and trimerize acetylenedicarboxamide. A resinous residue was formed which may have been a polyphthalocyanine but was not characterized. It appeared plausible to prealct that the reaction would 
work. Even though the reaction would be going from a stable diamide to an unstable dinitrile, which is unfarorable, the acetylenic dinitrile going to the stable hexacyanobenzene should be very favorable. The production of water in the dehydration should also be favorable. In addition to this, the formation of a polyphthalocyanine, which would most likely be even more stable because of its highly conjugated system, would increase the probability of the reaction. The blue compound prepared by the reaction of pyromellitic dianhydride with urea, borlc acld, and cupric chloride might possibly be a polyphthalocyanine. The reaction would not work under atmospheric pressure but was more successful under the pressure produced in a glass pressure bottle. This blue substance exhibited properties similar to copper phthalocyanine. It reprecipltated from sulfuric acid and was quite stable to heat.

In contrast to the product recelved from pyromellitic dianhydride, the same procedure with mellitic acld produced a derk brown substance which did not reprecipitate from sulfurlo acid. 


\section{SUMMARY}

1. A study was made of the effect of various concentrations of catalyst in the Diels' trimerization of the dimethyl ester of acetylenedicarboxylic acid. A solution of $0.5 \mathrm{~g}$. to $1.0 \mathrm{~g}$. of acetic acld-pyridine catalyst in $50 \mathrm{ml}$. of benzene gave the beat results.

2. The trimerization of butyne alnitrile in an attempt to prepare mellitonitrile ylelded a solld crystalline compound containing nitrogen. The compound was not characterized.

3. Oxidation of the products of the trimerization reactions ylelded a compound belleved to be mellitic acid. It melted at $280^{\circ} \mathrm{C}$ to $281^{\circ} \mathrm{C}$. (uncorr.). The melting point of mellitic acla as reported in the literature is $286^{\circ} \mathrm{C}$.

4. The reaction of pyromeliftic dianhydride with urea and cupric chloride yielded a phthalocyanine-like compound. It might possibly have been a linear polymer.

5. Melitic acid, urea, and cupric chloride yielded a compound which was dark brown in color and did not reprecipltate from gulfuric acid. 


\section{ACKNOWLEDGMENTS}

The author wisher to express grat1tude to Dr. Eugene c. Winslow for his suggestion of the problem and his personal understanding and advice concerning this investigation. The author also wishes to thank Eleanor A. Antonelli for her ald in preparing this thesis. Apprecietion is also expressed to the Research Corporation for their grant in support of this research. 
1. Braun, A., and Tcherniac, J., Ber., 40, 2709 (1907).

2. Chalgneau, M., Compt. rend., 233, 692-694 (1951).

3. Copenhaver, J.W., and Bigelow, M. H., Acetylene and Carbon Monoxide Chemistry, Rheinhold Publishing Corp., New York, (1949), p. 190.

4. Dahlen, M. A., Ind. and Eng. Chem., 3I, 839 (1939).

5. Diels, 0., Ber., 25, 1466, (1942).

6. Felet, P., Ber., 68, 1941, (1935).

7. Hasbrouck, Thesis, Cornell University Library, (1941).

8. Karmrodt, C., Ann., 81, 168-169 (1852).

9. Linstead, R. P., and Lowe, A. R., J. Cher. Soc., 1934, 1024 .

10. Masterson, J.E., Master's Thesis, University of Rhode Island (1951).

11. Molvally, W. J., Senior Research Report (unpublished), Univereity of Rhode Island (1949). 12. Meyer, H., and Steiner, K., Monatschefte, 25, 391-406

13. Megridichian, $\nabla .$, The Chemigtry of the Organic Gyanogen Compounde, Reinhold Publishing corp. New Iork, (1947), p. 3 .

14. Moureu, C., and Bongrand, J. C., Ann. Chim., 14, 9 (1920).

15. Nelson, D. A., Master's Thesis, University of Rhode Island (1955):

16. Robertson, J.M., J. Chem. Soc., 1936, 1195-1209.

17. Smith, L. H., Synthetic Fiber Developments in Germany, Textlie Research Institute, (1946), p. 539.

18. W11lams, J. I., An Introduction to Chromatography. Chemical Publighing Co., Inc., Brookign, (1947), p. 22. 